\title{
Influence of the Mg-content on ESR- Signals in Synthetic Calcium Carbonate
}

\author{
M. BARABAS, A. BACH, M. MUDELSEE and A. MANGINI
}

Heidelberger Akademie der Wissenschaften, Im Neuenheimer Feld 366, 6900 Heidelberg. F.R.G.

\begin{abstract}
Carbonate crystals doped with various concentrations of $\mathrm{Mg}^{2+}$-ions have been grown by a gel-diffusion method. An increase of the $\mathrm{Mg} / \mathrm{Ca}$-ratio to more than about 1 caused a phase change in the crystal lattice from calcite to aragonite. The properties of the ESR-signais of the synthetic carbonates were studied and compared with natural marine carbonates. The following results were derived:

(a) In the presence of $\mathrm{Mg}^{2+}$-ions the synthetic carbonates display the same ESR-signals as natural calcites of marine origin with similar properties (thermal stability, radiation sensitivity).

(b) The saturation value of the signal at $g=2.0006$ in synthetic calcites was found to be strongly related with the Mg-content in the crystals.

(c) The signal at $g=2.0036$ (axial symmetry) which is present in calcite was not influenced by the $\mathrm{Mg}$-concentration. Its saturation value decreases when the crystal phase changed from calcite to aragonite and in complement the signal at $g=2.0031$ appeared.
\end{abstract}

(d) The signals at $g=2.0057$ and $g=2.0031$ are most probably not of organic origin.

\section{Introduction}

Carbonate material that was formed in the ocean water (foraminifera, corals, moluscs) exhibits two narrow ESR-signals at $g=2.0057$ (hi) and $g=2.0006(\mathrm{~h} 3)$ and a sharp line at $g=2.0036$ (foraminifera) or at $g=2.0031$ (corals, molluscs*) (Yokoyama et al., 1983; Radtke and Grün, 1988; Skinner, 1983). Carbonates of continental origin (travertines, speleotherms) often show the signal at $g=2.0006$ too (Grün, 1989; Grün et al. 1988; Smith et al., 1985).

Little is known about the origin of these different signals. Generally, the radiation sensitive centers observed in carbonates are assumed to be anioncenters, i.e. centers derived from the host lattice anion $\left[\mathrm{CO}_{3}^{2-}\right]$ or $\left[\mathrm{HCO}_{3}^{-}\right]$and from impurity anions like $\left[\mathrm{PO}_{3}^{3-}\right],\left[\mathrm{AsO}_{2}^{2-}\right]$ or $\left[\mathrm{SO}_{3}^{3-}\right]$ (Marfunin, 1979; Cass et al., 1974; Serway and Marshall, 1967; Marshall and Serway, 1969). On the other hand impurity cations like $\mathrm{Y}^{3+}$ or $\mathrm{Li}^{+}$were reported to play an important role for stabilization of the different centers (Baquet et al., 1975; Marshall et al., 1968). Other centers which are commonly cited in alkali-halides like interstitials and ion vacancies (Royce, 1967) were not observed in carbonate spectra up to the present.

The relevant signals in the ESR-spectra of natural carbonates are:

*In molluses we find a strong superposition of the signal at $g=2.0006$ by a broad line around $g=2.0012$ and a sharp signal at $g=2.0018$ (Radtke et al.. 1985; Katzenberger et al., 1988) $-g=2.0057(\mathrm{hl}):$ This line earlier was attributed to a humic acid-clay complex (Grün and De Canniere, 1984). However, in 1985 De Canniere et al. claimed that this is improbable because they observed a similar signal $(g=2.0051)$ in synthetic calcite without organic matter.

$-g=2.0036$ : This signal was already observed to be the $g_{+}$of a center with $g_{i}=2.0021$ (De Canniere et al., 1985; Rossi et al., 1985) and attributed to the $\mathrm{CO}_{3}^{3-}$-center because of its close relation to $g$-values of that center observed by Servay and Marshall, (1967).

$-g=2.0031$ : This signal-observed in corals and molluscs-was attributed to alanine (in molluscs: Ikeya, 1981).

$-g=2.0006(\mathrm{~h} 3)$ : The most important signal for ESR-dating of carbonates could not be related to any known center. It was speculated to be a $\mathrm{CO}_{3}$-type center (Grün, 1989) although none of the known centers $\left(\mathrm{CO}_{2}^{2-}, \mathrm{CO}_{3}^{3-}, \mathrm{CO}_{3}^{-}\right)$fits this $g$-value (Marshall and McMillan, 1968; Servay and Marshall, 1967).

To get a better understanding of this problem the systematic approach is to study synthetic carbonate crystals grown under best controlled conditions. Besides spectra of chemical $\mathrm{CaCO}_{3}$ (Wieser et al., 1985) up to now only De Canniere et al. (1985, 1988) reported different spectra of synthetic carbonates. The main problem of synthetic growth is the purity of the ingredients used, because concentrations of impurities lower than $1 \mathrm{ppm}$ should be detectable 


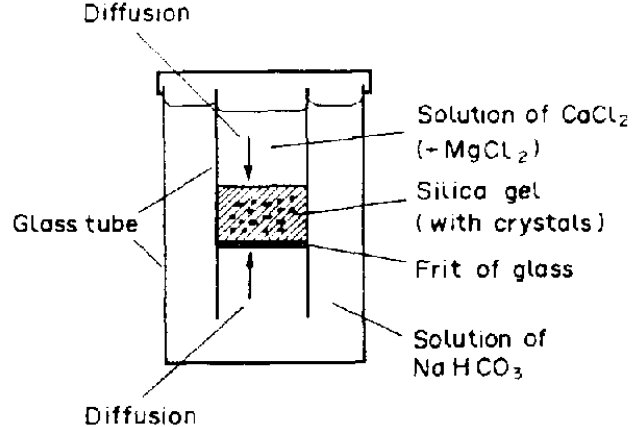

Fig. 1 . The crystals are growing in the silica-gel by diffusion

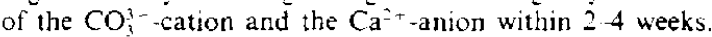

with ESR measurements (Plato and Schneider. 1971). In their experiment De Canniere et al. (1985) used concentrations of about $1 \%$ of humic acids for doping of the crystals in order to see detectable effects.

We present here ESR-powder-spectra of $\mathrm{Mg}^{\text {i+ }}$. doped carbonate crystals. The reasons for the choice of $\mathrm{Mg}$ in our first systematic approach are that:

(a) $\mathrm{Mg}^{2+}$-jons casily substitute for $\mathrm{Ca}$ in the lattice of calcite, for the size of this ion is smaller $(0.66 \hat{\AA})$ than that of $\mathrm{Ca}^{2}$ ( $1 \AA$ ) (Goldsmith and Graf. 1958).

(b) The amount of magnesium in ocean waterwhere most carbonates are generated-is five times that of calcium and the concentration of other cations (except $\mathrm{Na}$ ) is far smaller.

(c) The ratio of calcium and magnesium has a strong influence on the lattice structure of calcium carbonate: it determines whether calcite or aragonite crystals are grown (Folk and Land. 1972).

(d) Comparison of molluse and coral spectra show that the signal at $g=2.0006$ is largest in corals having the larger content of $\mathrm{Mg}^{2-}$.

(e) Our own preliminary experiments showed that the doping of crystals with $\mathrm{Mg}^{2+}$ suppresses the manganese lines and increases the signal at $g=2.0006$.

The range of $\mathrm{Mg}$ in natural carbonates is from about 100 ppm (molluscs) to $>10.000 \mathrm{ppm}$ (pricks of sea-urchin) (our own measurements).

The questions we address with our work are the following:

Is it possible to grow carbonate crystals exhibiting the same ESR-signals as natural carbonates?

- Can we detect any influence of impurity ions on the ESR signals?

... Is there a difference between signals in calcite and in aragonite?

-Why do most carbonates exhibit the signal at $g=2.0006$ but others do not?

-Can we get additional information on the nature of the different centers?

- Is it possible to draw conclusions for ESR-dating with carbonates?

\section{Experimental}

\subsection{Sinthesis of the carbonate cristals}

The crystals were grown using a gel-diffusionmethod (described in detail by Henisch. 1970) in at glass tube from solutions of $0.2 \mathrm{M} \mathrm{CaCl}_{2}$ and $0.2 \mathrm{M}$ $(\mathrm{NaH}) \mathrm{CO}_{3}$ separated by a gel made of $0.2 \mathrm{M} \mathrm{Na}$ meta-silicate (Fig. 1) at room temperature $(\mathrm{pH}=8$ ). The crystals grew at the diffusion front in the gel within 2-4 weeks up to a size of $0.2 \mathrm{~mm}$ (maximum about $2 \mathrm{~mm}$ ). The yield was between 100 and $200 \mathrm{mg}$ carbonate in each tube. The crystals were then washed from the gel with distilled water and dried at $60^{\circ} \mathrm{C}$.

We preferred this gel-diffusion-method for crystal formation because it is slower than the precipitation method (described by De Keyser and Degueldre. 1950; Wray and Daniels, 1957) and thus comes a little closer to crystal formation in nature. Additionally it is possible to dope the crystals continuousiy whilc growing by adding solutions of impurity ions. Onc disadvantage of this method is that a small amount of the sodium silicate gel $(<1 \%)$ may be incorporated in the crystals. Preliminary studies with precipitated crystals yielded ESR-spectra like those from chemical $\mathrm{CaCO}_{3}$ (see Wieser et al. 1985).

\subsection{Doped cristals}

Preliminary experiments were carried out with pure solutions of $\mathrm{CaCl}_{2}$ and $\mathrm{NaHCO}_{3}$ to which dissolved impurity ions in concentrations of about $\mathrm{I}_{\mathrm{O}}^{\mathrm{O}}\left(\mathrm{Al}^{3+}\right.$, $\mathrm{Sr}^{2+}, \mathrm{Mg}^{2+}, \mathrm{K}+\mathrm{NO}_{3}, \mathrm{SO}_{4}^{2-}$ ) were added. Some of the spectra are shown in Fig. 2. The main problem in this series were the large ESR-signals of manganese overlapping the other signals except for $\mathrm{CaCO}_{2}$ crystals that were doped with $\mathrm{Mg}^{2+}$ where the signal at $g=2.0006$ is also more pronounced.

In a second series of experiments we consequently used p.a. or suprapur substances with trace element concentrations $<5$ to $20 \mathrm{ppm}$ ( $\mathrm{Mn}$ : $5 \mathrm{ppm}$ ). The $\mathrm{Mn}$-lines in the ESR-spectra of these crystals were smaller by about a factor of 10 . We doped the solution of $\mathrm{CaCl}_{2}$ with solutions at 12 different concentrations of $\mathrm{MgCl}_{2}$, starting from a $\mathrm{MgCa}$ ratio of $4 \times 10^{-4}(100 \mathrm{ppm})$ to a $\mathrm{Mg} / \mathrm{Ca}$ ratio of 4 .

\subsection{AAS and $x$-ray diffraction}

The $\mathrm{Mg}^{2+}$-content of the crystals was measured subsequently by atomic absorption spectroscopy (AAS) at a precision of $5 \%$, because of the small sample weights used $(10 \mathrm{mg})$.

The crystal structure was checked with $x$-ray diffraction in order to determine the content of calcite and or aragonite in the crystals at least qualitatively.

\subsection{Gamma-ray irradiation and ESR-measurements}

All crystals were irradiated with a ${ }^{\text {(N) }} \mathrm{Co}$ source (dose rate about $50 \mathrm{~Gy} / \mathrm{min}$ ) in 5 steps up to $5 \mathrm{kGy}$ (which was expected to be the saturation level). After each irradiation step the samples were heated at 


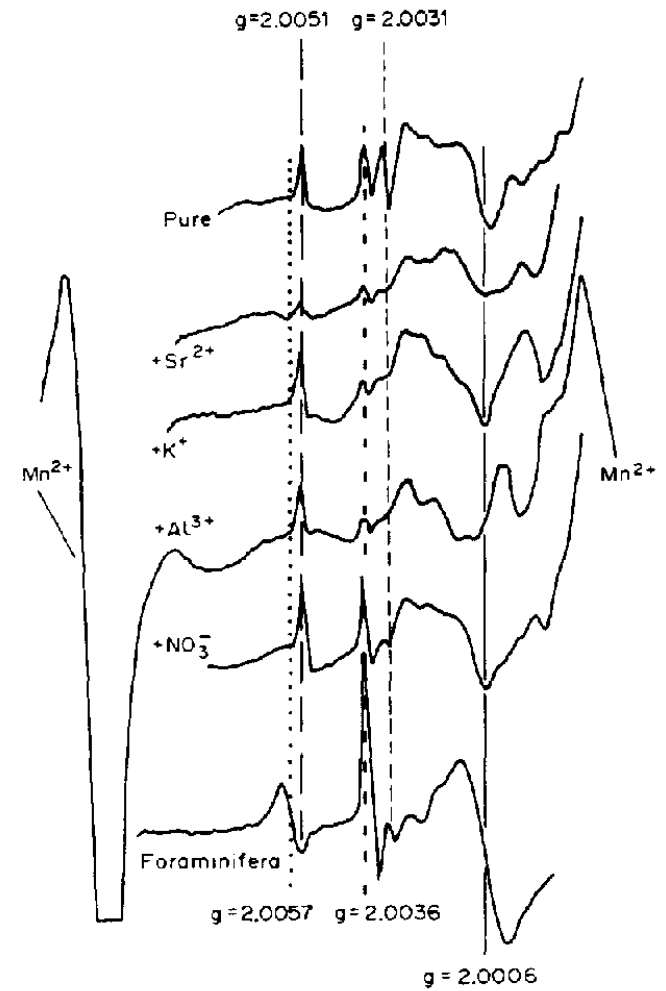

Fig. 2. The spectra shown are doped with various impurities in comparison with a spectrum of natural carbonate (foraminifera). They do not display the characteristic carbonate signals (except the signal at $g=2.0036$ ) and are superimposed by large $\mathrm{Mn}^{2+}$-hyperfine lines.

$160^{\circ} \mathrm{C}$ for $1 \mathrm{~h}$ to remove unstable signals. The ESRmeasurements were carried out at room temperature with a Bruker ESP-300 spectrometer (GSF, München) at 20 resp. $2 \mathrm{~mW}$ and $0.4 \mathrm{G}$ modulation amplitude in the range from $g=2.0100$ to $g=1.9980$. As no significant change in the signal width was observed we took the peak-to-peak height of the first derivative spectra as being proportional to the number of traps.

\subsection{Additional annealing experiments}

After these procedures the crystals were heated once at $184^{\circ} \mathrm{C}$ for $1 \mathrm{~h}$ to test the stability of the observed signals and compare it with that of natural samples. In two samples the signals have been completely annealed $\left(14 \mathrm{~h}\right.$ at $\left.200^{\circ} \mathrm{C}\right)$ and irradiated subsequently to test the regeneration behavior of the signals.

\section{Results and Discussion}

\subsection{Transfer of $\mathrm{Mg}^{2+}$-ions into the crystals}

The results of the AAS measurements are shown in Fig. 3. We used a log-log plot because of the large range of concentrations and of signals. We find a nearly linear relationship for low Mg-concentrations with a transfer factor of about 0.37 . Only the first

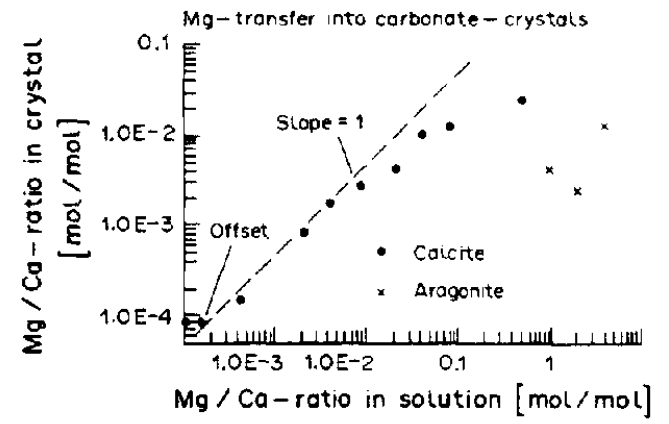

Fig. 3. Molecular ratio of $\mathrm{Mg} / \mathrm{Ca}$ in the crystals as determined by AAS measurements vs the molecular ratio of $\mathrm{Mg} / \mathrm{Ca}$ in the solution of $\mathrm{CaCl}_{2}$. For the samples with the highest $\mathrm{Mg}$-concentration aragonite was detected by $\mathrm{x}$-ray diffraction.

sample (with no $\mathrm{Mg}$ added) shows some deviation from this relationship. This offset may originate from a small $\mathrm{Mg}$ contamination (in the range of $50 \mathrm{ppm}$ ) in the solutions of $\mathrm{CaCl}_{2}$ and $(\mathrm{NaH}) \mathrm{CO}_{3}$ and in the gel respectively.

For higher $\mathrm{Mg}$-concentrations we find a sub-linear behavior up to a $\mathrm{Mg} / \mathrm{Ca}$ ratio of 0.5 (transfer factor decreases to about 0.05 ; see Katz, 1973:0.06 at $25^{\circ} \mathrm{C}$, at similar concentrations). Increase of the $\mathrm{Mg}$ concentration in the solution beyond this value does not lead to an increment of the magnesium content in the crystal: it decreases dramatically (by a factor of about 10). This is related with a transfer factor of about 0.0025 .

The observed behavior for crystals from $\mathrm{Mg}$ rich solutions indicates a phase change in the crystal lattice from calcite to aragonite which is expected for high magnesium content in the liquid (Folk, 1974). This was confirmed by $\mathrm{x}$-ray diffraction of the crystals: in the samples plotted with an astcrisk the content of aragonite in the crystals exceeds $30 \%$ (increasing with $\mathrm{Mg}$-concentration), while the samples grown at lower Mg-concentration consist of almost pure calcite.

In the $\mathrm{Mg}$-doped solutions trace element concentrations are about $5 \times 10^{4}$ lower than $\mathrm{Mg}$.

\subsection{Comparison of ESR-spectra with natural carbonates}

The spectrum of crystals grown at low Mg-concentration $(1000 \mathrm{ppm})$ and irradiated with $500 \mathrm{~Gy}$ is compared with calcitic foraminifera ( $500 \mathrm{~Gy}$ ) in Fig. 4(a). Qualitatively, there is a very good correspondence of the three signals at $g=2.0006, g=2.0036$ (unsymmetrical, with a small line at $g=2.0021$ belonging to it) and $g=2.0057$. Additionally we find a small signal at $g=2.0051$ in the synthetic crystals, probably the same that was observed by De Canniere et al. (1985) in synthetic calcite and which is present in chemical $\mathrm{CaCO}_{3}$. This signal is only present in the crystal with lowest $\mathrm{Mg}$-concentrations.

The concordance between natural and artificial samples is also very good when we compare the 


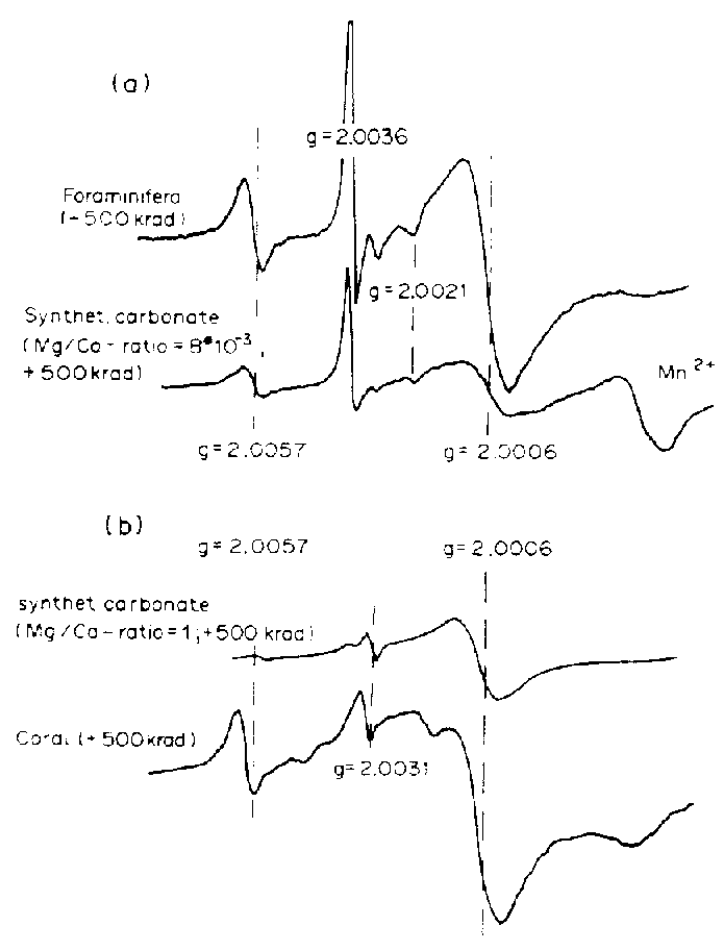

Fig. 4. Comparison of irradiated spectra of (a) synthetic crystals with low $\mathrm{Mg}$-content (calcitc) with foraminifera and (b) synthetic crystals with high $\mathrm{Mg}$-content (mainly aragonite) with corals. The concordance in both cases in relation to $g$-values and signal-widths is good

ESR-spectra of irradiated crystals doped with high $\mathrm{Mg}$-concentration ( $\mathrm{Mg} / \mathrm{Ca}$ ratio $=1$ in the solution) and spectra of aragonitic coral [Fig. 4(b)]. The only difference is the symmetric signal at $g=2.0031$ which was not present previously (and no signal at $g=2.0036)$

The signals show the same characteristics relative to microwave-power than natural samples: while the signals at $g=2.0057$ and $g=2.0006$ are not saturated up $1020 \mathrm{~mW}$. those at $g=2.0036$ and $g=$ 2.0031 saturate at low power labout 2 and $10 \mathrm{~mW}$ respectively).

This concordance of $g$-values and microwave dependency suggest that the growing conditions have been of such a kind that paramagnetic centers have been created that are very similar to those in natural material. This concordance was not observed for any of the crystals grown in the absence of $\mathrm{Mg}^{2}$ ' (Fig. 2). One important point to emphasize is the existence of the signal at $g=2.0057$ in artificial samples: although we cannot definitely exclude the presence of any organic material in the synthetic crystals. it seems unlikely that organic matter is the origin of this signal.

*For low Mg-concentrations the signal seems to decrease a little for the last irradiation step.

tThe saturation dose $D_{\mathrm{e}}$ is defined as the dose required to reach the saturation level multiplied by $(1-1 / e)$.

\subsection{Characteristics of the signais in sinthetic carbonates}

(i) Sensititity on irradiation. The $;$-ray irradiations were carried out in 4 steps $(0.5$ I 3.5 kGy). Shortly after irradiation the crystals displayed large signals in the region of $g=2.002$. This was attributed to the unstable signal at $g=2.0023$ (meanlife: $2 y$ at $10 \mathrm{C}$, Hennig and Grün. 1983) which is well known from natural carbonates. This signal was sufficiently reduced after heating for 1 h at $160 \mathrm{C}$, so that it did not disturb mesurements of the signal at $g=2.0006$.

All signals (except at $g=2.0057$ ) grow with the absorbed dose and display a noticeable saturation behavior*. The measured signals were then fitted to a saturation function (Barabas et al., 1988) to determine its saturation value and saturation dose (assuming zero signal for non-irradiated samples). For the signal at $g=2.0006$ the saturation dose $D_{\mathrm{e}}+$ was $1.3 \pm 0.25 \mathrm{kG}$ for all samples except those three with the highest magnesium content. In these samples $D_{c}$ was about a factor of 2 larger. These values agree well with values in the region of $1.0 \mathrm{kGy}$ observed in foraminifera (own data).

For the signal at $g=2.0036$ the observed $D_{\mathrm{r}}$ was $3 \pm 1 \mathrm{kGy}$ and thus larger than the values for foraminifera $\left(D_{\mathrm{c}}=0.8 \mathrm{kGy}\right)$. The signal at $g=2.0031$ in comparison saturated very fast: its $D_{c}$ was distinctly less than $1 \mathrm{kGy}$. It exhibits a similar saturation behavior in corals (Grün. 1988). whereas in molluscs usually it is not increased by irradiation (Radtke it al. 1985 ).

The signal at $g=2.0057$ displayed a small increase (about $10 \%$ ) after cach irradiation step. This enlarge-

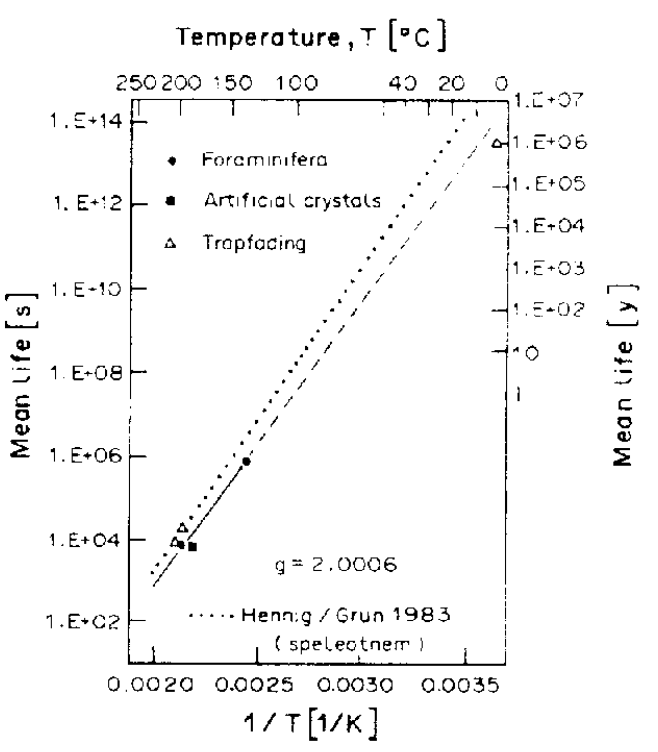

Fig. 5. Arrhenius plot of the signal at $g=2.0006$ in forminifera. For comparison the lifetime of the signal at $g=2.0006$ in synthetic crystals at $184 \mathrm{C}$ is shown. Additionally we have plotted the lifetimes of the traps responsible for this signal as derived from deep-sea foraminifera. 


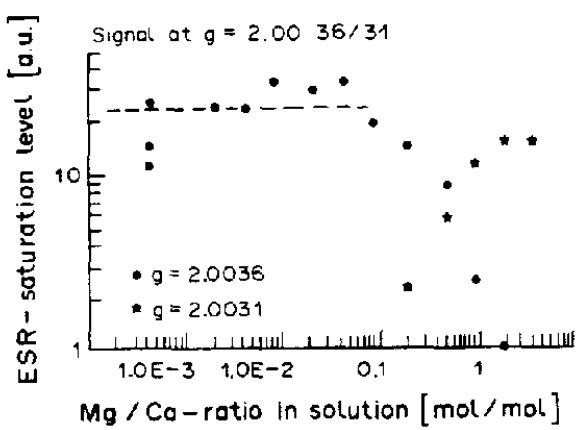

Fig. 6. Saturation values of the signals at $g=2.0036$ and $g=2.0031$ respectively vs the $\mathrm{Mg} / \mathrm{Ca}$-ratio of the $\mathrm{CaCl}_{2}$ solution. The change between these signals goes parallel to the phase change from calcite to aragonite

ment was attributed to the heat-treatment after irradiation (see next section).

(ii) Thermal stability. To check the thermal stability of the signals and to compare it with natural values, the samples were heated at $184^{\circ} \mathrm{C}$ for $1 \mathrm{~h}$. Results for $g=2.0006$ are shown in an Arrhenius plot (Fig. 5) together with new measurements from foraminifera. They exhibit almost identical values (lifetimes of the signal at $g=2.0036$ of natural and synthetic samples are both in the same range).

The signals at $g=2.0057$ of all crystals increased with this heat treatment by a factor of $1.9 \pm 0.4$. This increase is usually observed in natural carbonates (e.g. Yokoyama et al., 1983).

Summarizing, the ESR-signals of synthetic carbonates show the same behavior upon irradiation. and similar thermal stabilities, as natural carbonates.

\subsection{Dependency of the signals upon $\mathrm{Mg}^{2+}$-concen- tration}

To compare the amount of traps in the samples responsible for a certain signal, we assumed that the number of these traps is constant and that all of them can be filled upon (sufficient) irradiation. From the parameters of the fitted irradiation curve we can thus deduce relative values for the number of traps, i.e. the respective saturation level $S_{\mathrm{m}}$ (Barabas et al, 1988). These values were normalized to the specific density of the sample. The quotient $S_{\mathrm{m}} / D_{\mathrm{c}}$ gives the irradiation sensitivity of a specific signal.

(i) Signals at $g=2.0036$ and $g=2.0031$. In Fig. 6 the saturation values $S_{\mathrm{m}}$ of the signals at $g=2.0036$ and $g=2.0031$ are plotted together vs the $\mathrm{Mg} / \mathrm{Ca}$ ratio of the solution. Our results indicate that the value of the signal at $g=2.0036$ is virtually uninfluenced by the growing $\mathrm{Mg}$-concentration up to a $\mathrm{Mg} / \mathrm{Ca}$ ratio of 0.1 . Therefore we conclude that the $\mathrm{Mg}$-concentration does not influence the amount of traps responsible for the signal at $g=2.0036$. At

*The signal at $g=2.0057$ also increases with Mg-concentration by a factor of 5 . further increasing $\mathrm{Mg}$-concentratons in the solution the signal at $g=2.0036$ diminishes and disappears totally at a $\mathrm{Mg} / \mathrm{Ca}$-ratio of more than 1 .

While the signal at $g=2.0036$ decreases. the signal at $g=2.0031$ is not present at low $\mathrm{Mg}$ concentrations and increases for high $\mathrm{Mg}$-concentrations.

It is most probable that the described behavior of these signals corresponds to an observed phase change of the synthetic crystals from calcite to aragonite. This is also characteristic for natural calcitic samples (foraminifera) where the signal at $g=2.0036$ is present while natural aragonitic samples (corals) display the signal at $g=2.0031$

As reported by Rossi et al. (1986) the signal at $g=2.0036$ is the $g$-perpendicular of a paramagnetic site with $g$-parallel $=2.0021$. We came to similar conclusions for our natural and synthetic samples. The $\mathrm{CO}_{3}^{3-}$-center is most probabiy responsible for this signal (Servay and Marshall, 1967). Thus we deduce that this center, which displays axial symmetry in calcite, changes to cubic symmetry in aragonite exhibiting a $g$-factor $\frac{1}{3}\left(2 \times 2.0036^{2}+\right.$ $\left.2.0021^{2}\right)^{1 / 2} \approx 2.0031$ which agrees with the observed value. This may be due to larger inter-atomic distance in aragonite resulting in less interaction with the crystalline field (Plato and Schneider, 1971: Goldsmith and Graf, 1958). So, one and the same paramagnetic center could be responsible for the signals at $g=2.0036$ and at $g=2.0031$.

However, it is not yet clear which anion plays the role of stabilization of the center.

(ii) Signal at $g=2.0006$. The saturation level of the signal at $g=2.0006$ displays a quite different behavior with $\mathrm{Mg}$-increase [Fig. 7(a)]. Up to a $\mathrm{Mg} / \mathrm{Ca}$ ratio of 0.005 the signal seems to be unaffected by the $\mathrm{Mg}$ concentration but for higher concentrations it increases on a straight line with a slope between 0.5 (square-root) and 1 (linear). For a $\mathrm{Mg} / \mathrm{Ca}$ ratio $>0.5$ it displays a nearly constant value*.

The situation is similar if we look at the saturation values as a function of the $\mathrm{Mg}$-content in the crystals [Fig. 7(b)]. We find a nearly proportional increase of signal and $\mathrm{Mg}$-content, starting at a $\mathrm{Mg} / \mathrm{Ca}$-ratio of 0.001 to a ratio of about 0.02 (about $6000 \mathrm{ppm}$ ), which is the highest Mg-content observed in the synthetic crystals. At higher Mg-concentration of the solution, the Mg-content of the crystals decreases by about a factor of 10 and the signal height remains constant. The decrease of $\mathrm{Mg}$ in the crystals goes along with the observed phase change from calcite to aragonite.

Another important feature of this signal was described in detail by Barabas et al. (1988), the decrease of the saturation value by heating. Preliminary annealing experiments with our synthetic crystals confirm that the traps responsible for the signal at $g=2.0006$ disappear by heating, i.e. the saturation level $S_{\mathrm{m}}$ decreases with heating time, although the effect could not be quantified up to the present time. The same effect was observed for the saturation 

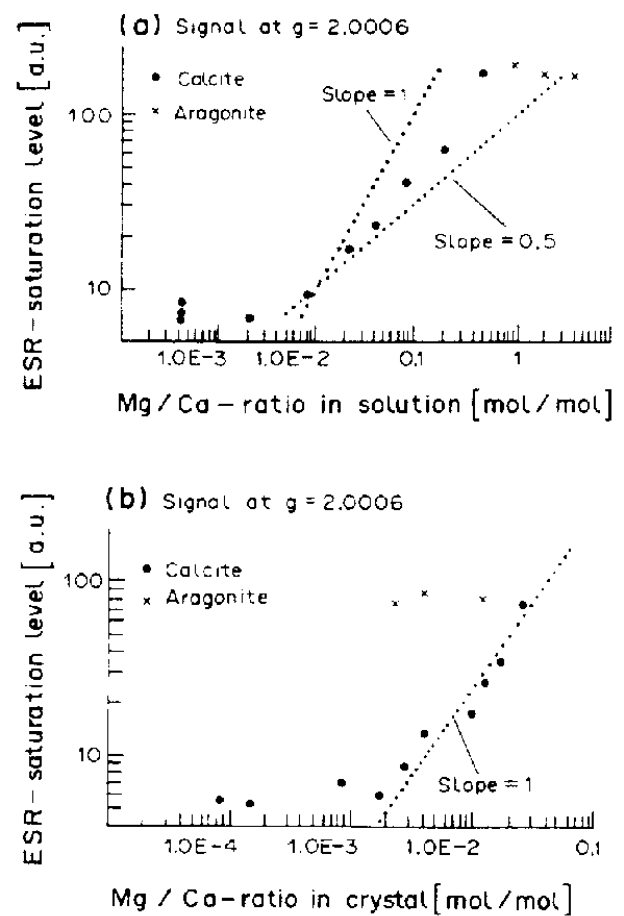

Fig. 7. Saturation values of the signal at $g=2.0006$ in synthetic crystal (a) as a function of $\mathrm{Mg} / \mathrm{Ca}$-ratio in the solution and (b) as a function of the $\mathrm{Mg} / \mathrm{Ca}$-ratio in the crystals.

levels of the signals at $g=2.0006$ in a deep-sea core (Barabas, 1989). The saturation levels of foraminifera -i.e. trap concentrations - decreased with the edge of the core. resulting in a lifetime of about $10^{\circ}$ years (at $2 \mathrm{C}$; Fig. 6), even though the $\mathrm{Mg}$ concentration remains constant

Although we do not yet know how the $\mathrm{Mg}^{2-}$-ions change the properties of the carbonate crystals our results indicate that it is the $\mathrm{Mg}$-content which is responsible for the signal at $g=2.0006$ observed in synthetic and natural carbonates.

\section{Conclusions}

We observe in synthetic carbonate crystals doped with $\mathrm{Mg}^{2+}$ :

(i) ESR-spectra which display signals at the same $g$-factors, and with same properties as in natural carbonates.

(ii) An increase of the signal at $g=2.0006$ with $\mathrm{Mg}$-concentration in the doping solution.

(iii) Change from the signal at $g=2.0036$ to $g=2.0031$ parallel to the phase change from calcite to aragonite.

Additionally the presence of the signals at $g=2.0057$ and $g=2.0031$ indicates that it is most probable that none of these signals originates from organic matter.

\section{Post scriptum}

Latest experiments show that it is indeed the $\mathrm{Mg}^{2+}$-presence and not the growing by gel-diffusion which influences the ESR-signal at $g=2.0006$. Carbonate crystals grown with the precipitation method (according to De Keyser and Degueldre. 1950) display the characteristic ESR-signals in the presence of $\mathrm{Mg}^{2+}$-ions as well

Acknowledgements--We thank A. Wieser (GSF. München) for assistance with the ESR-facility and gammatron. Also Professor Brunner (MPI f. mediz. Forschung. Heidelberg) who enabled us to use their ESR-facility. Thanks to $P$. Walter who made the $x$-ray diffraction medsurements. Financial support was given by the DFG

\section{References}

Baquet G., Dugas J., Escribe C.. Youdri L. and Belin C. (1975) ESR of $\mathrm{CO}_{3}^{3-\mathrm{Lj}^{+}}$in caicite. J. Phys. 36. 427.

Barabas M.. Bach A. and Mangini A. (1988) An analytical model for ESR-signals in calcite. Nucl. Tracks 14, 231.

Barabas M. (1989) ESR-Datierung van Karbonaten: Grundlagen, Systematik, Anwendingen. PhD Thesis, University of Heidelberg.

Cass J., Kent R. S., Marshall S. A. and Zager S. A. 11974) ESR of $\mathrm{HCO}_{3}^{2-}$ In irradiated calcite. J. Magn. Res. 14, 170.

De Canniere P., Joppart Th., Debuyst R., Dejehet F. and Apers D. (1986) ESR dating: a study of humic actd incorporated in synthetic calcite. PACT 10, 853 .

De Canniere P., Debuyst R., Dejehet F. and Apers D. (1988) ESR study of internally alpha-irradiated ( ${ }^{210} \mathrm{Po}$ nitrate doped) calcite single crystal. Nucl. Tracks 14, 267.

De Keyser W. L. and Degueldre L. (1950) Contribution à l'etude de la formation de la calcite, aragonite et vatérite. Bull. Soc. Chim. Beig. 59, 40.

Folk R. L. and Land S. C. (1972) $\mathrm{Mg} / \mathrm{Ca}$ versus salinity: a frame of reference for crystallisation of calcite, aragonite and dolomite (abs.). Geol. Soc. Am. Abs with Programsv. 4, 7.p. 508

Folk R. L. (1974) The natural history of calcium carbonate, effect of magnesium content and salinity. J Sediment. Petrol. 44, 40.

Goldsmith J. R. and Graf D. L. (1958) Relation between lattice constants and composition of the Ca-Mg-carbonates. Am. Mineral. 43, 84 .

Grün R. (1989) Die ESR-Altersberstimmungsmethode. Springer Verlag, Berlin.

Grün R. and De Canniere P. (1984) ESR-dating: Problems in the evaluation of the naturally accumulated dose (AD) in secondary carbonates. J. Radioanal. Nucl. Chem., Letters, 85, 213.

Grün R., Schwarez H. P., Ford D. C. and Hentzsch B (1988) ESR dating of spring deposited travertines. Quat Sci. Rev. 7, 429

Henisch H. K. (1970) Crystal Growth in Gels, $111 \mathrm{pp}$ Pennsylvania State University Press.

Hennig G. J. and Grün R. (1983) ESR-dating in quaternary geology. Quat. Sci. Ret. 2, 157

Ikeya M. (1981) Paramagnetic alanine molecular radicals in fossil shell and bones. Naturwissenschaften 67, 474.

Katz A. (1973) The interaction of magnesium with calcite during crystal growth at $25-90^{\circ} \mathrm{C}$ and one atmosphere. Geochim. Cosmochim. Acta 37, 1563.

Marfunin A. S. (1979) Spectroscopy, Luminescence and Radiation Centers in Minerals. Springer Verlag. Berlin.

Marshall S. A., McMillan J. A. and Serway R. A. (1968) ESR of $\mathrm{Y}^{3+}+$-stabilized $\mathrm{CO}_{3}^{3-} . J$. Chem. Phis. 48, 5131 .

Marshall S. A. and McMillan J. A. (1968) ESR absorption spectrum of $\mathrm{CO}_{-}^{-}$. J. Chem. Phys. 49, 4887. 
Marshall S. A. and Serway R. A. (1969) ESR of AsO2- in irradiated calcite. J. Chem. Phys. 50, 435.

Plato M. and Schneider F. (1971) Elektronen-Spin-Resonanz. Karl-Thiemig-Verlag. Mannheim.

Radtke U., Mangini A. and Grün R. (1985) ESR-dating of marine fossil shells. Nucl. Tracks 10, 879.

Radtke U. and Grün R. (1988) ESR dating of corals. Quart. Sci. Ret. In Press.

Rossi A., Poupeau G. and Danon J. (1985) On some paramagnetic species induced in natural calcites by betaand gamma-ray irradiations. ESR Dating and Dosimetry (Eds Ikeya M. and Miki T.). JONICS, Tokyo.

Royce B. S. H. (1967) The creation of point defects in alkali halides. Prog. Solid-state Chem. 4, 213

Serway R. A. and Marshall S. A. (1967) ESR absorption spectrum of orthorhombic $\mathrm{CO}_{3}^{-}$and $\mathrm{CO}_{3}^{-}$molecule ions in irradiated single crystal calcite. J. Chem. Phys. 46, 1949.
Smith B. W., Smart P. L. and Symons M. C. R. (1985) ESR signals in a variety of speleotherm calcites and their suitability for dating. Nucl. Tracks 10, 837 .

Skinner A. F. (1983) Overestimate of stalagmitic calcite ESR dates due to laboratory heating. Nature 304, 152.

Wieser A., Göksu H. Y. and Regulla D. F. (1985) Characteristics of gamma-induced ESR-spectra in various calcites. Nucl. Tracks 10, 83 I.

Wray J. L. and Daniels F. (1957) Precipitation of calcite and aragonite. J. Am. Chem. Soc. 79, 2031.

Yokoyama Y., Quaegebeur J. P., Bibron R. and Leger C. (1983) ESR dating of Paleolithic calcite: Thermal annealing experiment and trapped electron lifetime. PACT 2 , 371.

Yokoyama Y., Bibron R., Leger C. and Quaegebeur J. P. (1985) ESR dating of paleolithic calcite: fundamental studies. Nucl. Tracks 10, 929. 